\title{
Distribution of Intracranial Major Artery Stenosis/Occlusion According to RNF213 Polymorphisms
}

\author{
Jinkwon Kim ${ }^{1,2,+} \mathbb{D}$, Young Seok Park ${ }^{3,+}$, Min-Hee Woo ${ }^{2}$, Hui Jeong An ${ }^{4}$, Jung Oh Kim ${ }^{4}$, \\ Han Sung Park ${ }^{4}$, Chang Soo Ryu ${ }^{4}$, Ok Joon Kim ${ }^{2, *(D)}$ and Nam Keun Kim ${ }^{4, *(D)}$ \\ 1 Department of Neurology, Yongin Severance Hospital, Yonsei University College of Medicine, Yongin 16995, \\ Korea; antithrombus@gmail.com \\ 2 Department of Neurology, CHA Bundang Medical Center, CHA University, Seongnam 13496, Korea; \\ RA3520@chamc.co.kr \\ 3 Department of Neurosurgery, Chungbuk National University Hospital, Chungbuk National University, \\ College of Medicine, Cheongju 28644, Korea; youngseokparkmd@gmail.com \\ 4 Department of Biomedical Science, College of Life Science, CHA University, Seongnam 13488, Korea; \\ tody2209@naver.com (H.J.A.); jokim8505@gmail.com (J.O.K.); hahnsung@naver.com (H.S.P.); \\ regis2040@nate.com (C.S.R.) \\ * Correspondence: okjun77@cha.ac.kr (O.J.K.); nkkim@cha.ac.kr (N.K.K.); \\ Tel.: +82-31-780-5481 (O.J.K.); +82-31-881-7137 (N.K.K.) \\ + J.K. and Y.S.P. contributed equally to this work.
}

Received: 18 January 2020; Accepted: 10 March 2020; Published: 13 March 2020

\begin{abstract}
Intracranial major artery stenosis/occlusion (ICASO) is the major cause of ischemic stroke. Recent studies have suggested that variants of RNF213, a susceptibility gene for moyamoya disease (MMD), are also related to non-MMD ICASO. Regarding the predominant involvement of steno-occlusion on anterior circulation in MMD, we hypothesized that the ICASO distribution pattern (anterior/posterior) in non-MMD may differ according to RNF213 variants. This study analyzed 1024 consecutive Korean subjects without MMD who underwent computed tomography angiography (CTA) or magnetic resonance angiography (MRA). We evaluated four single nucleotide polymorphisms (SNPs) in the exon region of RNF213: 4448G > A (rs148731719), 4810G > A (rs112735431), 4863G > A (rs760732823), and 4950G > A (rs371441113). Associations between RNF213 variants and anterior/posterior ICASO were examined using multivariate logistic regression analysis. Anterior ICASO was present in $23.0 \%$ of study subjects, and posterior ICASO was present in $8.2 \%$. The GA genotype of RNF213 4810G > A (adjusted odds ratio (AOR) [95\% confidence interval (CI)], 2.39 [1.14-4.87] compared to GG; $p=0.018$ ) and GA genotype of RNF213 4950G > A (AOR [95\% CI], 1.71 [1.11-2.63] compared to GG; $p=0.015$ ) were more frequent in subjects with anterior ICASO. The genotype frequency of RNF213 4863G > A differed significantly according to the presence of posterior ICASO. Further investigations of the functional and biological roles of RNF213 will improve our understanding of the pathomechanisms of ICASO and cerebrovascular disease.
\end{abstract}

Keywords: intracranial major artery stenosis/occlusion; RNF-213; moyamoya disease; single nucleotide polymorphism

\section{Introduction}

Intracranial major artery stenosis/occlusion (ICASO) is the major cause of ischemic stroke [1,2]. ICASO can result from atherosclerosis, thromboembolism, or non-atherosclerotic vascular disease, such as dissection, vasculitis, or moyamoya disease (MMD) [3]. Really interesting new gene (RING) 
finger protein 213 (RNF213) is encoded by the RNF213 gene (DDBJ/EMBL/GenBank accession number AB537889) on chromosome 17q25, which has received considerable attention as a susceptibility gene for MMD and ICASO in Asians [4-6]. The functional role of RNF213 on cerebral vasculature has not been established, but experimental studies have suggested that it affects cerebral blood perfusion, angiogenesis, and oxygen consumption [7-10].

ICASO can be present in anterior and posterior cerebral circulation. It has been known that anterior and posterior ICASO differs in clinical characteristics, risk factors, histopathology, and genetic susceptibility [11-13]. RNF213 is recognized as the major susceptibility gene for MMD, which is typically characterized by progressive steno-occlusive changes in the terminal part of the internal carotid arteries and/or their branches (anterior circulation) [14,15]. Regarding the potential genetic contributions to ICASO, we hypothesized that the distribution of anterior/posterior ICASO in non-MMD may also differ according to genetic variants of RNF213. To test our hypothesis, we assessed the association between four single nucleotide polymorphisms (SNPs) in the exon region of RNF213 (4448G > A, $4810 \mathrm{G}>\mathrm{A}, 4863 \mathrm{G}>\mathrm{A}$, and 4950G > A) and the distribution pattern of ICASO in non-MMD Koreans.

\section{Results}

\subsection{Characteristics}

This study included 1024 non-MMD subjects (636 ischemic stroke and 388 non-stroke subjects) who underwent genotyping of RNF213 variants and angiographic evaluation. Their mean age was $63.6 \pm 11.4$ years, and $47.0 \%$ were male. Baseline characteristics of the study subjects are shown in Table 1. ICASO was present in $27.6 \%$. Compared with subjects without ICASO, those with ICASO were more likely to be older and have hypertension, diabetes mellitus (DM), and ischemic stroke. Regarding the distribution of ICASO, $23.0 \%$ of subjects had anterior ICASO, and $8.2 \%$ had posterior ICASO.

Table 1. Clinical characteristics of study subjects.

\begin{tabular}{|c|c|c|c|c|}
\hline Variable & $\begin{array}{c}\text { Total } \\
n=1024\end{array}$ & $\begin{array}{c}\text { ICASO (-) } \\
n=788\end{array}$ & $\begin{array}{c}\text { ICASO (+) } \\
n=236\end{array}$ & $p$-Value ${ }^{1}$ \\
\hline Sex, male & $481(47.0)$ & $353(47.6)$ & $128(45.2)$ & 0.535 \\
\hline Age, years & $63.6 \pm 11.4$ & $62.5 \pm 11.5$ & $66.2 \pm 10.4$ & $<0.001$ \\
\hline \multicolumn{5}{|l|}{ Medical history } \\
\hline Hypertension & $542(52.9)$ & $373(50.3)$ & $169(59.7)$ & 0.009 \\
\hline Diabetes mellitus & $214(20.9)$ & $138(18.6)$ & $76(26.9)$ & 0.005 \\
\hline Hypercholesterolemia & $280(27.3)$ & $195(26.3)$ & $85(30.0)$ & 0.265 \\
\hline Atrial fibrillation & $59(5.8)$ & $38(5.1)$ & $21(7.4)$ & 0.208 \\
\hline Ischemic stroke & $636(62.1)$ & $386(52.1)$ & $250(88.3)$ & $<0.001$ \\
\hline $\mathrm{ICASO}$ in anterior cerebral circulation ${ }^{\dagger}$ & $236(23.0)$ & - & $236(83.4)$ & - \\
\hline ICASO in posterior cerebral circulation $\ddagger$ & $84(8.2)$ & - & $84(29.7)$ & - \\
\hline
\end{tabular}

Note: Data are expressed as numbers (\%) or mean \pm standard deviation. ICASO, intracranial major artery stenosis/occlusion. ${ }^{1}$ Comparison between ICASO $(-)$ and ICASO $(+) .{ }^{\dagger}$ Intracranial internal carotid artery, anterior cerebral artery, or middle cerebral artery. $¥$ Intracranial vertebral artery, basilar artery, or posterior cerebral artery.

\subsection{RNF213 Genotypes}

Table 2 shows the genotype frequencies of the RNF213 variants. For RNF213 4448G > A, the frequency of minor allele (A) was $7.7 \%$. The minor allele (A) frequencies of $4810 \mathrm{G}>\mathrm{A}, 4863 \mathrm{G}>\mathrm{A}$, and $4950 \mathrm{G}>\mathrm{A}$ were $2.0 \%, 11.7 \%$, and $7.0 \%$, respectively. Carrier frequencies of at least one A allele (minor allele) for the four SNPs were 14.9\%, 4.0\%, 22.2\%, and 13.6\%. The distribution of RNF213 polymorphisms satisfied the Hardy-Weinberg equilibrium. 
Table 2. Genotypes of RNF213 variants.

\begin{tabular}{|c|c|c|c|c|}
\hline \multirow[b]{2}{*}{ Genotype } & \multicolumn{4}{|c|}{ RNF213 Single Nucleotide Polymorphism (RefSNP Number) } \\
\hline & $\begin{array}{c}4448 G>A \\
\text { (rs148731719) }\end{array}$ & $\begin{array}{c}4810 G>A \\
(\text { rs112735431) }\end{array}$ & $\begin{array}{c}4863 G>A \\
(\text { rs760732823) }\end{array}$ & $\begin{array}{c}4950 G>A \\
(r s 371441113)\end{array}$ \\
\hline GG & $826(85.1)$ & $983(96.0)$ & $755(77.8)$ & $839(86.4)$ \\
\hline GA & $140(14.4)$ & $41(4.0)$ & $204(21.0)$ & $128(13.2)$ \\
\hline AA & $5(0.5)$ & $0(0)$ & $12(1.2)$ & $4(0.4)$ \\
\hline$p$-value for test of HWE & $>0.999$ & $>0.999$ & 0.7582 & $>0.999$ \\
\hline
\end{tabular}

\subsection{Relationship between RNF213 Genotypes and ICASO}

Table 3 shows the genotype distribution of RNF213 variants according to the presence of ICASO.

Table 3. Genotype distribution of RNF213 variants according to the presence of ICASO.

\begin{tabular}{|c|c|c|c|c|c|c|}
\hline \multirow{2}{*}{$\begin{array}{c}\text { RNF213 } \\
\text { Polymorphism } \\
\text { (RefSNP Number) }\end{array}$} & \multicolumn{6}{|c|}{ Genotype Frequency (GG/GA/AA) } \\
\hline & ICASO (-) & ICASO (+) & $\begin{array}{c}\text { Anterior } \\
\text { ICASO (-) }\end{array}$ & $\begin{array}{c}\text { Anterior } \\
\text { ICASO (+) }\end{array}$ & $\begin{array}{l}\text { Posterior } \\
\text { ICASO (-) }\end{array}$ & $\begin{array}{c}\text { Posterior } \\
\text { ICASO (+) }\end{array}$ \\
\hline $\begin{array}{c}4448 \mathrm{G}>\mathrm{A} \\
(\mathrm{rs} 148731719)\end{array}$ & $596 / 100 / 3$ & $230 / 40 / 2$ & $638 / 103 / 4$ & $188 / 37 / 1$ & $753 / 132 / 4$ & $73 / 8 / 1$ \\
\hline $\begin{array}{c}4810 G>A \\
(\operatorname{rs} 112735431)\end{array}$ & $716 / 25 / 0$ & $267 / 16 / 1$ & $762 / 26 / 0$ & $221 / 15 / 1$ & $703 / 37 / 0$ & $80 / 4 / 1$ \\
\hline $\begin{array}{c}4863 \mathrm{G}>\mathrm{A} \\
(\mathrm{rs} 760732823)\end{array}$ & $535 / 158 / 6$ & $220 / 46 / 6$ & $576 / 161 / 8$ & $179 / 43 / 4$ & $684 / 198 / 7$ & $71 / 6 / 5$ \\
\hline $\begin{array}{c}4950 \mathrm{G}>\mathrm{A} \\
(\mathrm{rs} 371441113)\end{array}$ & $613 / 83 / 3$ & $226 / 45 / 1$ & $655 / 86 / 4$ & $184 / 42 / 0$ & $767 / 119 / 3$ & $72 / 9 / 1$ \\
\hline
\end{tabular}

Note: Data are expressed as numbers. ICASO, intracranial major artery stenosis/occlusion.

We investigated the relationships between distributions of the four RNF213 variants and the presence of ICASO using multivariate logistic regression analysis (Table 4). Patients with ICASO were more likely to have the RNF213 4810 (rs112735431) GA genotype than the GG genotype, but the association was not statistically significant (adjusted odds ratio (AOR) [95\% confidence intervals (CI)], 2.05 [0.98-4.21]; $p=0.053$ ). None of the other RNF213 variants were associated with the presence of ICASO.

Table 4. Risk of ICASO according to genotype of RNF213 variants.

\begin{tabular}{|c|c|c|c|c|c|c|c|}
\hline \multirow{2}{*}{$\begin{array}{c}\text { RNF213 } \\
\text { Polymorphism }\end{array}$} & \multirow{2}{*}{ Genotype } & \multicolumn{2}{|c|}{ ICASO } & \multicolumn{2}{|c|}{ Anterior ICASO } & \multicolumn{2}{|c|}{ Posterior ICASO } \\
\hline & & $\begin{array}{c}\text { AOR } \\
(95 \% \mathrm{CI})\end{array}$ & $p$-Value & $\begin{array}{c}\text { AOR } \\
(95 \% \mathrm{CI})\end{array}$ & $p$-Value & $\begin{array}{c}\text { AOR } \\
(95 \% \mathrm{CI})\end{array}$ & $p$-Value \\
\hline \multirow{5}{*}{$\begin{array}{c}4448 \mathrm{G}>\mathrm{A} \\
(\mathrm{rs} 148731719)\end{array}$} & GG & 1.00 (ref) & - & 1.00 (ref) & - & 1.00 (ref) & - \\
\hline & GA & $\begin{array}{c}1.21 \\
(0.79-1.86)\end{array}$ & 0.388 & $\begin{array}{c}1.43 \\
(0.92-2.21)\end{array}$ & 0.109 & $\begin{array}{c}0.74 \\
(0.32-1.53)\end{array}$ & 0.454 \\
\hline & $\mathrm{AA}$ & $\begin{array}{c}1.51 \\
(0.23-9.98)\end{array}$ & 0.671 & $\begin{array}{c}0.71 \\
(0.04-5.27)\end{array}$ & 0.769 & $\begin{array}{c}2.32 \\
(0.11-17.92)\end{array}$ & 0.473 \\
\hline & $\begin{array}{l}\text { Dominant (GG } \\
\text { vs. GA + AA) }\end{array}$ & $\begin{array}{c}1.22 \\
(0.79-1.86)\end{array}$ & 0.356 & $\begin{array}{c}1.40 \\
(0.90-2.14)\end{array}$ & 0.131 & $\begin{array}{c}0.80 \\
(0.36-1.60)\end{array}$ & 0.562 \\
\hline & $\begin{array}{l}\text { Recessive (GG } \\
+ \text { GA vs. AA) }\end{array}$ & $\begin{array}{c}1.46 \\
(0.18-9.83)\end{array}$ & 0.693 & $\begin{array}{c}0.67 \\
(0.03-4.97)\end{array}$ & 0.732 & $\begin{array}{c}2.41 \\
(0.12-18.64)\end{array}$ & 0.451 \\
\hline \multirow{3}{*}{$\begin{array}{c}4810 G>A \\
(r s 112735431)^{2}\end{array}$} & GG & 1.00 (ref) & - & 1.00 (ref) & - & 1.00 (ref) & - \\
\hline & GA & $\begin{array}{c}2.05 \\
(0.98-4.21)\end{array}$ & 0.053 & $\begin{array}{c}2.39 \\
(1.14-4.87)\end{array}$ & 0.018 & $\begin{array}{c}1.23 \\
(0.35-3.35)\end{array}$ & 0.708 \\
\hline & $\mathrm{AA}$ & NA & & NA & & NA & \\
\hline
\end{tabular}


Table 4. Cont.

\begin{tabular}{|c|c|c|c|c|c|c|c|}
\hline \multirow{2}{*}{$\begin{array}{c}\text { RNF213 } \\
\text { Polymorphism }\end{array}$} & \multirow[b]{2}{*}{ Genotype } & \multicolumn{2}{|c|}{ ICASO } & \multicolumn{2}{|c|}{ Anterior ICASO } & \multicolumn{2}{|c|}{ Posterior ICASO } \\
\hline & & $\begin{array}{c}\text { AOR } \\
(95 \% \text { CI })\end{array}$ & $p$-Value & $\begin{array}{c}\text { AOR } \\
(95 \% \text { CI })\end{array}$ & $p$-Value & $\begin{array}{c}\text { AOR } \\
(95 \% \text { CI })\end{array}$ & $p$-Value \\
\hline \multirow{5}{*}{$\begin{array}{c}\text { 4863G > A } \\
\text { (rs760732823) }\end{array}$} & GG & 1.00 (ref) & - & 1.00 (ref) & - & 1.00 (ref) & - \\
\hline & GA & $\begin{array}{c}0.69 \\
(0.47-1.02)\end{array}$ & 0.067 & $\begin{array}{c}0.86 \\
(0.57-1.28)\end{array}$ & 0.467 & $\begin{array}{c}0.29 \\
(0.11-0.64)^{1}\end{array}$ & 0.005 \\
\hline & AA & $\begin{array}{c}2.96 \\
(0.79-11.24)\end{array}$ & 0.104 & $\begin{array}{c}1.66 \\
(0.44-6.27)\end{array}$ & 0.453 & $\begin{array}{c}8.55 \\
(2.17-32.51)^{1}\end{array}$ & 0.002 \\
\hline & $\begin{array}{l}\text { Dominant (GG } \\
\text { vs. GA + AA) }\end{array}$ & $\begin{array}{c}0.76 \\
(0.52-1.10)\end{array}$ & 0.157 & $\begin{array}{c}0.90 \\
(0.61-1.32)\end{array}$ & 0.588 & $\begin{array}{c}0.52 \\
(0.25-0.98)^{1}\end{array}$ & 0.043 \\
\hline & $\begin{array}{l}\text { Recessive (GG } \\
\text { + GA vs. AA) }\end{array}$ & $\begin{array}{c}3.19 \\
(0.86-12.12)\end{array}$ & 0.081 & $\begin{array}{c}1.72 \\
(0.42-6.27)\end{array}$ & 0.425 & $\begin{array}{c}10.32 \\
(2.62-39.22)^{1}\end{array}$ & $<0.001$ \\
\hline \multirow{5}{*}{$\begin{array}{c}4950 G \text { > A } \\
\text { (rs371441113) }\end{array}$} & GG & 1.00 (ref) & - & 1.00 (ref) & - & 1.00 (ref) & - \\
\hline & GA & $\begin{array}{c}1.43 \\
(0.93-2.19)\end{array}$ & 0.100 & $\begin{array}{c}1.71 \\
(1.11-2.63)^{1}\end{array}$ & 0.015 & $\begin{array}{c}0.82 \\
(0.36-1.63)\end{array}$ & 0.589 \\
\hline & AA & $\begin{array}{c}0.49 \\
(0.02-3.98)\end{array}$ & 0.542 & NA & \multirow{3}{*}{0.033} & $\begin{array}{c}2.28 \\
(0.11-19.34)\end{array}$ & 0.489 \\
\hline & $\begin{array}{l}\text { Dominant (GG } \\
\text { vs. GA + AA) }\end{array}$ & $\begin{array}{c}1.38 \\
(0.90-2.10)\end{array}$ & 0.133 & $\begin{array}{c}1.59 \\
(1.03-2.44)^{1}\end{array}$ & & $\begin{array}{c}0.87 \\
(0.40-1.70)\end{array}$ & 0.700 \\
\hline & $\begin{array}{l}\text { Recessive (GG } \\
+ \text { GA vs. AA) }\end{array}$ & $\begin{array}{c}0.46 \\
(0.02-3.74)\end{array}$ & 0.510 & NA & & $\begin{array}{c}2.35 \\
(0.11-19.90)\end{array}$ & 0.473 \\
\hline
\end{tabular}

Note: Data are adjusted odds ratios (AOR) and 95\% confidence intervals (CI) derived from multivariate logistic regression models adjusting for sex, age, and presence of hypertension, diabetes mellitus, hypercholesterolemia, atrial fibrillation, or ischemic stroke. ICASO, intracranial major artery stenosis/occlusion; NA, not applicable (no cases in the arm). ${ }^{1} p$-value $<0.05 .{ }^{2}$ For RNF213 4810G $>\mathrm{A}$, analysis for dominant and recessive models was omitted due to there being no subject with AA genotype.

\subsection{Relationship between RNF213 Genotypes and Anterior/Posterior ICASO}

When we evaluated the relationship between RNF213 variants and the distribution of ICASO (anterior/posterior) using the multivariate logistic regressions (Table 4), anterior ICASO was significantly associated with the RNF213 4810 (rs112735431) GA genotype (AOR [95\% CI], 2.39 [1.14-4.87]; $p=0.018$ ) compared with the GG genotype. Anterior ICASO was also significantly more likely with the RNF213 4950 (rs371441113) GA genotype (AOR [95\% CI], 1.71 [1.11-2.63]; $p=0.015$ ) compared with the GG genotype. In the analysis regarding the posterior ICASO, the presence of posterior ICASO was significantly associated with the RNF213 4863 (rs760732823) genotype. Compared with the RNF213 4863 GG genotype, the GA genotype was associated with lower likelihood of posterior ICASO (AOR [95\% CI], 0.29 [0.11-0.64]; $p=0.005)$, but the AA genotype was associated with higher odds of posterior ICASO (AOR [95\% CI], 8.55 [2.17-32.51]; $p=0.002$ ).

\subsection{Haplotype Analysis}

We evaluated the linkage disequilibrium of the RNF213 variants (4448G > A (rs148731719)/4810G $>\mathrm{A}(\mathrm{rs} 112735431) / 4863 \mathrm{G}>\mathrm{A}(\mathrm{rs} 760732823) / 4950 \mathrm{G}>\mathrm{A}(\mathrm{rs} 371441113))$ using the Haploview program (Figure 1). Among the four SNPs, there was a strong linkage disequilibrium (0.73 of $\mathrm{D}^{\prime}$ statistic and 0.480 of $r^{2}$ ) between loci 4448G > A (rs148731719) and 4950G > A (rs371441113). Other combinations of RNF213 SNPs did not exhibit strong linkage disequilibrium.

We performed haplotype analyses of the four SNPs for the presence of ICASO, anterior ICASO, and posterior ICASO (Table 5). In the haplotype analyses, GAGG (4448G/4810A/4863G/4950G) was associated with a significantly increased risk of ICASO and anterior ICASO. Other combinations did not show significant association with ICASO distribution. 


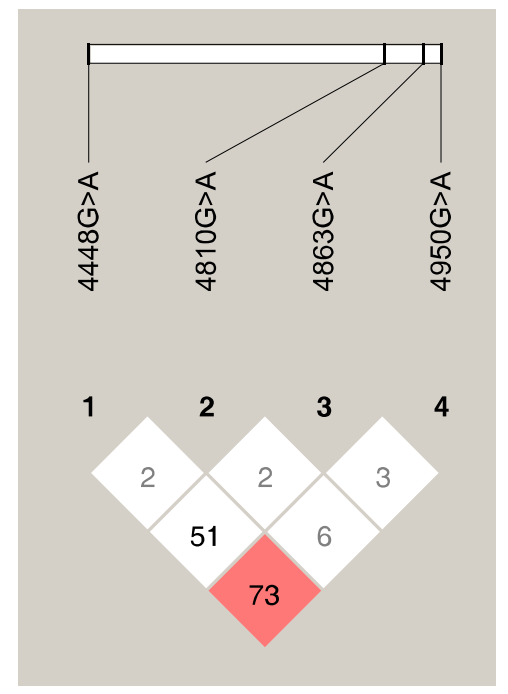

Figure 1. Linkage disequilibrium plot of four RNF213 single nucleotide polymorphisms. The linkage disequilibrium between each single nucleotide polymorphism (SNP) is measured as the $\mathrm{D}^{\prime}$ statistic $(\times 100)$, shown in the diamond at the intersection of the diagonals of the two corresponding SNPs. Strong linkage disequilibrium is represented in red, and weak linkage disequilibrium is represented in white.

Table 5. Haplotype analysis of RNF213 variants for the presence of ICASO.

\begin{tabular}{|c|c|c|c|c|c|c|c|}
\hline \multirow{2}{*}{$\begin{array}{c}\text { Haplotype } \\
\text { RNF } 213 \\
4448 / 4810 / 4863 / 4950\end{array}$} & \multirow[b]{2}{*}{ Frequency } & \multicolumn{2}{|c|}{ ICASO } & \multicolumn{2}{|c|}{ Anterior ICASO } & \multicolumn{2}{|c|}{ Posterior ICASO } \\
\hline & & $\begin{array}{c}\text { AOR } \\
(95 \% \mathrm{CI})\end{array}$ & $p$-Value & $\begin{array}{c}\text { AOR } \\
(95 \% \mathrm{CI})\end{array}$ & $p$-Value & $\begin{array}{c}\text { AOR } \\
(95 \% \mathrm{CI})\end{array}$ & $p$-Value \\
\hline GGGG & 0.784 & 1.00 (ref) & - & 1.00 (ref) & - & 1.00 (ref) & - \\
\hline AGGA & 0.047 & $\begin{array}{c}1.26 \\
(0.76-2.10)\end{array}$ & 0.371 & $\begin{array}{c}1.37 \\
(0.81-2.32)\end{array}$ & 0.246 & $\begin{array}{c}1.01 \\
(0.46-2.24)\end{array}$ & 0.978 \\
\hline AGGG & 0.024 & $\begin{array}{c}1.02 \\
(0.45-2.30)\end{array}$ & 0.964 & $\begin{array}{c}1.41 \\
(0.64-3.13)\end{array}$ & 0.398 & $\begin{array}{c}0.31 \\
(0.04-2.35)\end{array}$ & 0.258 \\
\hline GAGG & 0.014 & $\begin{array}{c}2.86 \\
(1.15-7.11)\end{array}$ & 0.023 & $\begin{array}{c}4.01 \\
(1.63-9.87)\end{array}$ & 0.002 & $\begin{array}{c}1.28 \\
(0.33-4.97)\end{array}$ & 0.725 \\
\hline GGAG & 0.104 & $\begin{array}{c}0.87 \\
(0.59-1.28)\end{array}$ & 0.472 & $\begin{array}{c}0.95 \\
(0.64-1.43)\end{array}$ & 0.811 & $\begin{array}{c}0.88 \\
(0.49-1.59)\end{array}$ & 0.680 \\
\hline Rare * & 0.016 & $\begin{array}{c}1.43 \\
(0.48-4.28)\end{array}$ & 0.518 & $\begin{array}{c}2.06 \\
(0.69-6.12)\end{array}$ & 0.193 & $\begin{array}{c}0.62 \\
(0.08-4.88)\end{array}$ & 0.646 \\
\hline
\end{tabular}

Note: Adjusted odds ratio (AOR) and 95\% confidence interval (CI) were computed for each haplotype and compared to the most common haplotype (GGGG). Adjustments were made for sex, age, and the presence of hypertension, diabetes mellitus, hyperlipidemia, atrial fibrillation, or ischemic stroke. ICASO, intracranial major artery stenosis/occlusion. * Other rare combinations besides the above haplotypes.

\section{Discussion}

In the current study, we evaluated the distribution of four polymorphisms in the exon sequence of RNF213, the MMD susceptibility gene, and the relationship between these polymorphisms and ICASO in non-MMD Koreans. We found that RNF213 4810G > A (rs112735431) and 4950G > A (rs371441113) were significantly associated with the presence of anterior ICASO, whereas RNF213 4863G > A (rs760732823) was associated with posterior ICASO. If further studies validate the relationship between the RNF213 variants and anterior/posterior ICASO, detection of RNF213 variants could be applicable to a screening method for ICASO or prediction of disease prognosis. Discovery of a pathogenic role of RNF213 gene in ICASO may provide a novel therapeutic target in ICASO with high risk for stroke.

The RNF213 gene encodes a RING finger protein that possesses both ubiquitin ligase activity and ATPases associated with diverse cellular activities' (AAA+) ATPase activity [16]. Although RNF213 variants have been associated with various vascular disorders, the mechanisms through 
which they contribute to these disorders are unknown [17]. Experimental reports have suggested multiple pathogenic mechanisms involving endothelial function, smooth muscle cell proliferation, inflammatory signaling pathways, hemostasis, angiogenesis, vascular remodeling, and response to hypoxia [7,9,10,18-22]. However, an RNF213-deficient mouse model did not exhibit any vascular abnormality [23]. Currently, the exact biochemical and pathologic roles of RNF213 in vascular disorders remain controversial.

Beyond conflicting reports regarding the functional role of RNF213, epidemiologic data have shown significant associations between RNF213 variants and intracranial vascular disorders including MMD, ICASO, cerebral artery dissection, and intracranial aneurysm [4,24-26]. At least 24 genetic changes in RNF213 have been associated with MMD [21]. The RNF213 4810G > A (rs112735431) is considered a major genetic risk factor for MMD; the carrier rate of this SNP in East Asians with MMD is $>70 \%[18,27,28]$. Although the RNF213 4810G > A variant has never been detected in Caucasians, there are rare missense RNF213 variants, which have been associated with MMD in Caucasians, especially those with childhood-onset or familial disease $[29,30]$. Beyond the association with MMD, a number of studies have reported frequent RNF213 variants in patients with non-MMD ICASO [2,31,32]. In a meta-analysis of 11 studies including 1778 ICASO patients and 3140 controls in East Asians, RNF213 4810G > A was significantly associated with an increased risk of ICASO [17]. High-resolution magnetic resonance angiography (MRA) showed that ICASO with RNF213 4810G > A was associated with a negative remodeling pattern, which is a hallmark of MMD, in contrast to the positive remodeling pattern of classical atherosclerotic ICASO [33]. In addition to the relationship with the presence of intracranial cerebrovascular disease, RNF213 variant genotypes may also be associated with the disease progression and long-term outcome. Among patients with MMD, the homozygous variant of RNF213 4810G > A was associated with an increased likelihood of onset at a younger age, cerebral infarction at diagnosis, and cognitive impairment during long-term follow-up [34]. In a study of 59 relatives of patients with MMD, RNF213 4810G > A heterozygous carriers had a higher risk of developing ICASO during angiographic follow-up [35]. The presence of RNF213 4810G > A variant was at increased risk for ischemic stroke, which was largely attributable to large-artery atherosclerosis [36]. Recent reports have also described associations between RNF213 variants and extracranial systemic vasculopathy involving coronary, renal, and pulmonary arteries [37-39].

Because of the predominant involvement of the anterior cerebral circulation in MMD, we hypothesized that the distribution pattern of ICASO may differ according to RNF213 variants. In our results, we found that RNF213 4810G > A (rs112735431) and 4950G > A (rs371441113) increased the likelihood of anterior ICASO. Both of these variants have been reported to be significantly associated with MMD in Korean and Chinese populations [18,21,40,41]. Similarly, there was a study of 221 Japanese patients, which found that RNF213 4810G > A was significantly associated with anterior ICASO but not posterior ICAS [42]. In the case-control study with a total of 46,958 Japanese people, RNF213 4810G $>$ A variant carriers more frequently had intracranial anterior circulation stenosis than non-carriers $(60.0 \%$ versus $27.3 \%, p=0.004)$ [36]. Another study of 70 early-onset stroke patients with ICASO in Japan found that 17 RNF213 4810G > A carriers had anterior ICASO, whereas only 1 carrier of this variant had posterior ICASO as well, and the RNF213 4810G > A variant was more common in patients with MCA or ACA stenosis (17/44) than in patients with posterior ICASO (1/11) [43]. However, there have also been negative reports indicating that the distribution of anterior and posterior ICASO did not differ between RNF213 variant carriers and non-carriers [2,32]. The inconsistent results between studies may be attributed to differences in study populations; the two negative reports included only ICASO (+) subjects and compared the distribution of anterior and posterior ICASO according to RNF213 variants. Because of our limited understanding of the pathogenetic role of RNF213 and insufficient clinical data, it is difficult to make conclusions regarding the relationships between RNF213 variants and distribution patterns of ICASO. However, predominant involvement of the anterior cerebral circulation in carriers with RNF213 variants of 4810G > A and 4950G > A suggests an inter-relationship between ICASO and MMD and the possibility of a shared genetic pathomechanism. 
In the current study, the presence of posterior ICASO differed significantly according to the genotype distribution of RNF213 4863G > A (rs760732823). As underlying risk factors and genetic predisposition differ between anterior and posterior ICASO, RNF213 variants may have divergent effects on the anterior and posterior cerebral circulations [13]. To our knowledge, no prior report has shown a significant relationship between RNF213 variants and posterior ICASO. Interestingly, compared with the GG wild type of 4863G > A (rs760732823), the GA genotype was associated with a lower risk of posterior ICASO, but the AA genotype was associated with a higher risk. Compared with RNF213 4810 (rs112735431) and 4950 (rs371441113), which are both susceptibility genes for MMD, little is known about RNF213 4863G > A (rs760732823). We previously evaluated the distribution of RNF213 4863G > A between Korean MMD patients and controls; there was no significant difference according to RNF213 4863G > A [21]. More research is required to verify whether the relationship between RNF213 4863G > A and posterior ICASO is duplicated in other study populations.

We acknowledge potential limitations of this study. Although many studies have reported associations between RNF213 variants and cerebrovascular disorders, the underlying pathogenic process has not been established. Without understanding the pathogenetic mechanisms, our data from case-control design could not access the causal relationship between RNF213 variants and ICASO. Furthermore, ICASO and MMD, both RNF213-related disorders, are progressive cerebrovascular diseases $[35,44]$. Because our study lacked follow-up data, we did not provide information about the progression of ICASO or the prognostic value of RNF213 variants. ICASO is a heterogeneous disease, influenced by various environmental and genetic factors [2,45]. Although atherosclerotic stenosis of a major intracranial artery is the most common type of ICASO, different etiologies and risk factors can influence the development of ICASO [4,31]. We adjusted for multiple conventional vascular risk factors, but the possibility of unknown potential confounding factors remains. Although we excluded MMD patients based on angiographic findings, it is possible that patients with early changes or atypical patterns of MMD might have been included, which may have contributed to the association between ICASO and RNF213 variants $[17,31,33]$. In addition, the study was performed at a single hospital, and a large portion of the study participants had ischemic stroke. Thus, the distribution of RNF213 variants in our subjects may have differed from that in the general population of Koreans. Further analysis according to the degree of ICASO was lacking in the current study. Use of statins, antiplatelets, and anti-hypertensive agents may influence the development and progression of ICASO. Unfortunately, due to the limitations of the retrospective design, we could not collect the data for medications. As the pathogenesis of MMD is known to be ethnically diverse, the effect of RNF213 variants on ICASO may have varied in other populations [26]. Moreover, the low prevalence of RNF213 variants and the small sample size of this study may have limited the statistical power to detect differences between subgroups and gene-environmental interactions. We assessed four SNPs in the current study, but there are other potential susceptibility variants in RNF213. To overcome the potential limitations and to improve our understanding of the influence of RNF213 on ICASO, a wide range of research is required to explore the genetic pathogenesis and epidemiology of this common cerebrovascular disorder.

\section{Methods}

\subsection{Study Subjects}

Study subjects were consecutively recruited from the Department of Neurology at CHA Bundang Medical Center, CHA University (an 800-bed teaching hospital in Gyeonggi-do, South Korea), between 2001 and 2010 (Figure 2). Subjects were selected from those who underwent blood sampling for genotyping and cerebral angiographic evaluation by MRA or computed tomography angiography (CTA). Patients with proximal carotid artery occlusion were excluded because the proximal carotid occlusion often does not allow the evaluation of intracranial arteries. Individuals who satisfied the criteria for definite MMD were excluded from the study $[43,46]$. The medical records were reviewed to identify the presence of hypertension, DM, hyperlipidemia, atrial fibrillation, or ischemic stroke. 
Hypertension was defined as use of antihypertensive medication or a resting systolic blood pressure $\geq 140 \mathrm{mmHg}$ or resting diastolic blood pressure $\geq 90 \mathrm{mmHg}$ on repeated measurements. DM was defined as use of antidiabetic medications or a fasting plasma glucose $\geq 7.0 \mathrm{mmol} / \mathrm{L}$ or glycosylated hemoglobin $\geq 6.5 \%$. Hypercholesterolemia was defined as use of lipid-lowering agents or a low-density lipoprotein cholesterol $\geq 4.1 \mathrm{mmol} / \mathrm{L}$ or total cholesterol $\geq 6.2 \mathrm{mmol} / \mathrm{L}$. Ischemic stroke was defined as acute neurological dysfunction of vascular origin, confirmed by brain magnetic resonance imaging or computed tomography. All participants provided written informed consent. The study was approved by the Institutional Review Board of CHA Bundang Medical Center (BD2012-136D).

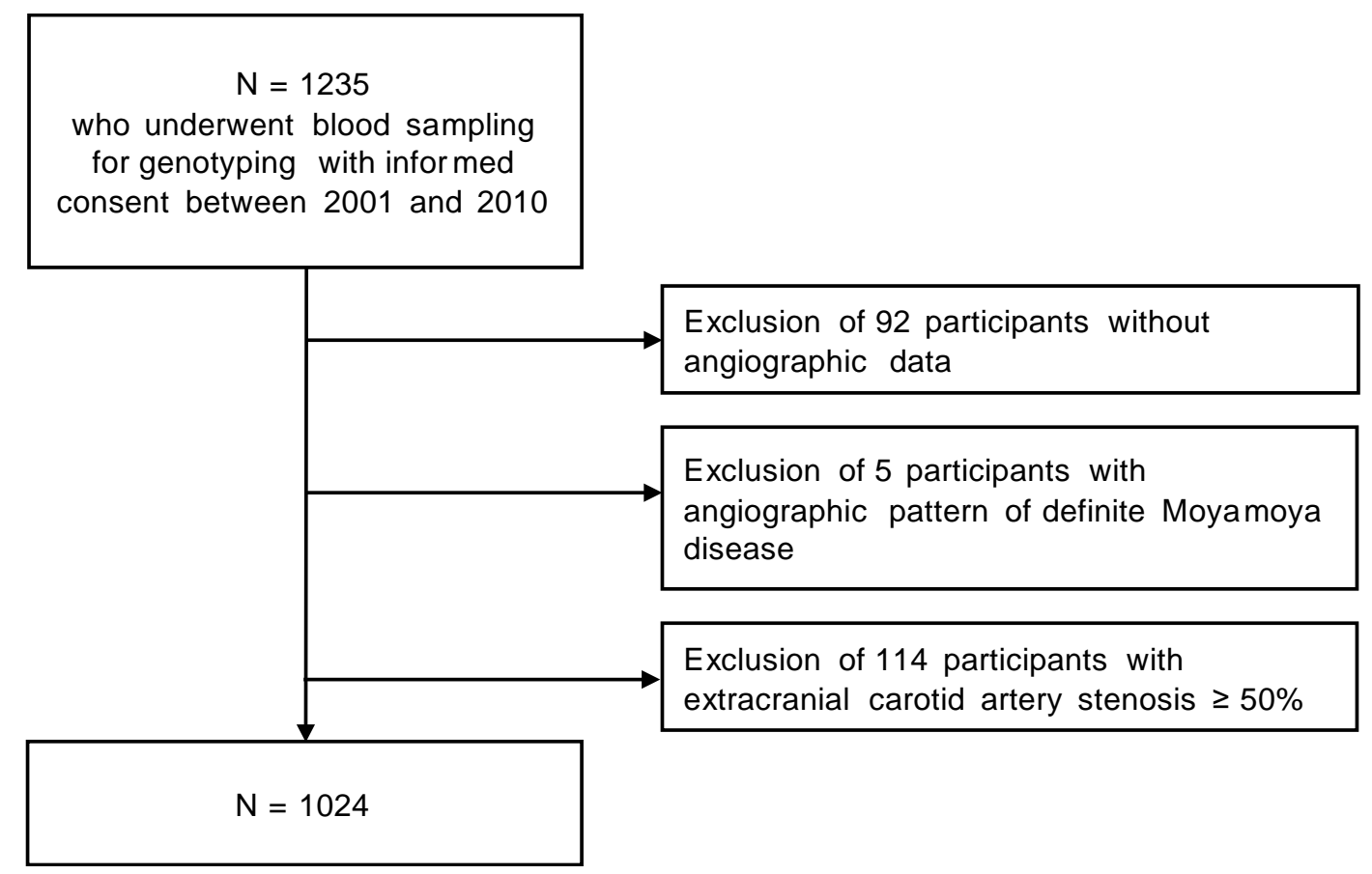

Figure 2. Flowchart of study participant inclusion and exclusion.

\subsection{Distribution of ICASO}

Angiographic data (MRA or CTA) of the intracranial cerebral arteries were evaluated by two neurologists (J.K., M.H.W.). ICASO was defined as occlusion or $\geq 50 \%$ stenosis in the intracranial portion of internal carotid artery (ICA), middle cerebral artery (MCA), anterior cerebral artery (ACA), posterior cerebral artery (PCA), vertebral artery (VA), or basilar artery (BA). The degree of stenosis in each intracranial cerebral artery was measured using the Warfarin vs. Aspirin for Symptomatic Intracranial Disease method [47]. According to the intracranial angiographic findings, the presence of "anterior ICASO" (involving the ICA, ACA, or MCA) and "posterior ICASO" (involving the PCA, VA, or BA) was recorded.

\subsection{Genotyping of RNF213 Variants}

In our prior study, we identified four SNPs in the exon region of RNF213: 4448G > A (rs148731719), 4810G > A (rs112735431), 4863G > A (rs760732823), and 4950G > A (rs371441113) based on prior reports in Asians and a literature review [21]. Information regarding the SNPs was obtained from the HapMap database (http://hapmap.ncbi.nlm.nih.gov/). For genotyping of these SNPs, DNA was extracted from peripheral blood samples using the G-DEX blood extraction kit (iNtRON Biotechnology, Inc., Seongnam, Korea) according to the manufacturer's instructions. RNF213 variants were detected by polymerase chain reaction-restriction fragment length polymorphism (PCR-RFLP) analysis. RNF213 4810G > A (rs112735431) was evaluated in all study subjects $(n=1024)$, whereas $4448 \mathrm{G}>\mathrm{A}(\mathrm{rs} 148731719)$, 
4863G > A (rs760732823), and 4950G > A (rs371441113) were assessed in 971 subjects. For each SNP, we randomly repeated approximately $10 \%$ of the PCR assays and evaluated concordance with DNA sequencing using an automatic sequencer (ABI3730 $\times 1$ DNA analyzer; Applied Biosystems, Foster City, CA, USA). Concordance of these quality control samples was $100 \%$. Details regarding the genotyping methodology and the RNF213 SNP primer sequences were previously reported [21].

\subsection{Statistical Analysis}

The characteristics were expressed as mean \pm standard deviation for continuous variables (age) and number (\%) for categorical variables. Comparison of characteristics between groups were performed with independent t-test (continuous variables) or chi-squared test (categorical variables). RNF213 SNP genotype frequencies were evaluated using the Hardy-Weinberg equilibrium test, which satisfied the Hardy-Weinberg equilibrium. To assess the relationships between RNF213 variants and the presence of anterior/posterior ICASO, we calculated AOR and 95\% CI using multivariate logistic regression analysis with the presence of anterior/posterior ICASO as the dependent variable. Regression models were adjusted for sex, age, and the presence of hypertension, DM, hyperlipidemia, atrial fibrillation, and ischemic stroke. The statistical analysis was performed with $\mathrm{R}$ software version 3.5.1 (The R Foundation for Statistical Computing, Vienna, Austria; http://www.R-project.org/). Linkage disequilibrium maps of RNF213 variants were generated using Haploview version 4.2 (https://www.broadinstitute.org/haploview/haploview) [48]. Two-sided $p$-value $<0.05$ was considered statistically significant.

\section{Conclusions}

RNF213 variants (4810G > A and 4950G > A) were significantly associated with anterior ICASO. Conversely, the RNF213 4863G > A variant was significantly associated with posterior ICASO. Our findings suggest a pathogenetic role of RNF213 in ICASO. There is a clear need for further investigations elucidating the functional role of RNF213 to better understand the underlying pathogenesis for cerebrovascular disease.

Author Contributions: Study concept and design, J.K., Y.S.P., N.K.K.; acquisition of the data; M.-H.W., Y.S.P., O.J.K.; performing the experiments: M.-H.W., H.J.A., J.O.K., H.S.P., C.S.R.; statistical analysis and data interpretation: J.K., H.J.A., J.O.K., H.S.P., C.S.R.; writing—original draft preparation: J.K., Y.S.P.; writing-review and editing: O.J.K., N.K.K.; funding acquisition, Y.S.P., N.K.K. All authors have read and agreed to the published version of the manuscript.

Funding: This work was partly supported by the National Research Foundation of Korea (NRF ICT 2016H1D5A1908909 and 2016R1D1A1B03930141) and partly supported by a grant from the Korea Healthcare Technology R\&D Project, Ministry for Health, Welfare \& Family Affairs, Republic of Korea (HI18C19990200).

Conflicts of Interest: The authors declare no conflict of interest.

\section{Abbreviations}

$\begin{array}{ll}\text { AOR } & \text { Adjusted odds ratio } \\ \text { CI } & \text { Confidence interval } \\ \text { CTA } & \text { Computed tomography angiography } \\ \text { DM } & \text { Diabetes mellitus } \\ \text { HWE } & \text { Hardy-Weinberg equilibrium } \\ \text { MMD } & \text { Moyamoya disease } \\ \text { MRA } & \text { Magnetic resonance angiography } \\ \text { PCR-RFLP } & \text { Polymerase chain reaction-restriction fragment length polymorphism } \\ \text { RNF213 } & \text { RING finger protein 213 gene } \\ \text { SNP } & \text { Single nucleotide polymorphism }\end{array}$




\section{References}

1. Suri, M.F.K.; Qiao, Y.; Ma, X.; Guallar, E.; Zhou, J.; Zhang, Y.; Liu, L.; Chu, H.; Qureshi, A.I.; Alonso, A.; et al. Prevalence of Intracranial Atherosclerotic Stenosis Using High-Resolution Magnetic Resonance Angiography in the General Population: The Atherosclerosis Risk in Communities Study. Stroke 2016, 47, 1187-1193. [CrossRef] [PubMed]

2. Liao, X.; Zhang, T.; Li, B.; Hu, S.; Liu, J.; Deng, J.; Tan, H.; Yan, J. Rare RNF213 variants and the risk of intracranial artery stenosis/occlusion disease in Chinese population: A case-control study. BMC Med. Genet. 2019, 20, 55. [CrossRef] [PubMed]

3. Miyawaki, S.; Imai, H.; Shimizu, M.; Yagi, S.; Ono, H.; Mukasa, A.; Nakatomi, H.; Shimizu, T.; Saito, N. Genetic variant RNF213 c.14576G >A in various phenotypes of intracranial major artery stenosis/occlusion. Stroke 2013, 44, 2894-2897. [CrossRef] [PubMed]

4. Miyawaki, S.; Imai, H.; Takayanagi, S.; Mukasa, A.; Nakatomi, H.; Saito, N. Identification of a genetic variant common to moyamoya disease and intracranial major artery stenosis/occlusion. Stroke 2012, 43, 3371-3374. [CrossRef] [PubMed]

5. Park, M.-G.; Shin, J.-H.; Lee, S.W.; Park, H.R.; Park, K.-P. RNF213 rs112735431 polymorphism in intracranial artery steno-occlusive disease and moyamoya disease in Koreans. J. Neurol. Sci. 2017, 375, 331-334. [CrossRef] [PubMed]

6. Wang, Y.; Mambiya, M.; Li, Q.; Yang, L.; Jia, H.; Han, Y.; Liu, W. RNF213 p.R4810K Polymorphism and the Risk of Moyamoya Disease, Intracranial Major Artery Stenosis/Occlusion, and Quasi-Moyamoya Disease: A Meta-Analysis. J. Stroke Cereb. Dis. 2018, 27, 2259-2270. [CrossRef] [PubMed]

7. Morimoto, T.; Enmi, J.-I.; Hattori, Y.; Iguchi, S.; Saito, S.; Harada, K.H.; Okuda, H.; Mineharu, Y.; Takagi, Y.; Youssefian, S.; et al. Dysregulation of RNF213 promotes cerebral hypoperfusion. Sci. Rep. 2018, 8, 3607. [CrossRef]

8. Kobayashi, H.; Kabata, R.; Kinoshita, H.; Morimoto, T.; Ono, K.; Takeda, M.; Choi, J.; Okuda, H.; Liu, W.; Harada, K.H.; et al. Rare variants in RNF213, a susceptibility gene for moyamoya disease, are found in patients with pulmonary hypertension and aggravate hypoxia-induced pulmonary hypertension in mice. Pulm. Circ. 2018, 8. [CrossRef]

9. Banh, R.S.; Iorio, C.; Marcotte, R.; Xu, Y.; Cojocari, D.; Rahman, A.A.; Pawling, J.; Zhang, W.; Sinha, A.; Rose, C.M.; et al. PTP1B controls non-mitochondrial oxygen consumption by regulating RNF213 to promote tumour survival during hypoxia. Nat. Cell Biol. 2016, 18, 803-813. [CrossRef]

10. Kobayashi, H.; Matsuda, Y.; Hitomi, T.; Okuda, H.; Shioi, H.; Matsuda, T.; Imai, H.; Sone, M.; Taura, D.; Harada, K.H.; et al. Biochemical and Functional Characterization of RNF213 (Mysterin) R4810K, a Susceptibility Mutation of Moyamoya Disease, in Angiogenesis In Vitro and In Vivo. J. Am. Heart Assoc. 2015, 4, e002146. [CrossRef]

11. Roth, W.; Morgello, S.; Goldman, J.; Mohr, J.P.; Elkind, M.S.V.; Marshall, R.S.; Gutierrez, J. Histopathological Differences Between the Anterior and Posterior Brain Arteries as a Function of Aging. Stroke 2017, 48, 638-644. [CrossRef]

12. Gorelick, P.; Wong, K.S.; Liu, L. Epidemiology. In Frontiers of Neurology and Neuroscience; Karger: Basel, Switzerland, 2016; Volume 40, pp. 34-46. ISBN 1660-4431.

13. Kim, J.S.; Nah, H.-W.; Park, S.M.; Kim, S.-K.; Cho, K.H.; Lee, J.; Lee, Y.-S.; Kim, J.; Ha, S.-W.; Kim, E.-G.; et al. Risk factors and stroke mechanisms in atherosclerotic stroke: Intracranial compared with extracranial and anterior compared with posterior circulation disease. Stroke 2012, 43, 3313-3318. [CrossRef]

14. Kim, J.S. Moyamoya Disease: Epidemiology, Clinical Features, and Diagnosis. J. Stroke 2016, 18, 2-11. [CrossRef] [PubMed]

15. Luisa, S.F.; Rizzo, A.; Bedini, G.; Capone, F.; Di Lazzaro, V.; Nava, S.; Acerbi, F.; Rossi, D.S.; Binelli, S.; Faragò, G.; et al. Microduplication of 15q13.3 and Microdeletion of 18q21.32 in a Patient with Moyamoya Syndrome. Int. J. Mol. Sci. 2018, 19, 3675.

16. Morito, D.; Nishikawa, K.; Hoseki, J.; Kitamura, A.; Kotani, Y.; Kiso, K.; Kinjo, M.; Fujiyoshi, Y.; Nagata, K. Moyamoya disease-associated protein mysterin/RNF213 is a novel AAA+ ATPase, which dynamically changes its oligomeric state. Sci. Rep. 2014, 4, 4442. [CrossRef] [PubMed] 
17. Liao, X.; Deng, J.; Dai, W.; Zhang, T.; Yan, J. Rare variants of RNF213 and moyamoya/non-moyamoya intracranial artery stenosis/occlusion disease risk: A meta-analysis and systematic review. Environ. Health Prev. Med. 2017, 22, 75. [CrossRef] [PubMed]

18. Liu, W.; Morito, D.; Takashima, S.; Mineharu, Y.; Kobayashi, H.; Hitomi, T.; Hashikata, H.; Matsuura, N.; Yamazaki, S.; Toyoda, A.; et al. Identification of RNF213 as a susceptibility gene for moyamoya disease and its possible role in vascular development. PLOS ONE 2011, 6, e22542. [CrossRef]

19. Ma, Y.-G.; Zhang, Q.; Yu, L.-B.; Zhao, J.-Z. Role of Ring Finger Protein 213 in Moyamoya Disease. Chin. Med. J. 2016, 129, 2497-2501. [CrossRef]

20. Hitomi, T.; Habu, T.; Kobayashi, H.; Okuda, H.; Harada, K.H.; Osafune, K.; Taura, D.; Sone, M.; Asaka, I.; Ameku, T.; et al. Downregulation of Securin by the variant RNF213 R4810K (rs112735431, G > A) reduces angiogenic activity of induced pluripotent stem cell-derived vascular endothelial cells from moyamoya patients. Biochem. Biophys. Res. Commun. 2013, 438, 13-19. [CrossRef]

21. Park, Y.S.; An, H.J.; Kim, J.O.; Kim, W.S.; Han, I.B.; Kim, O.J.; Kim, N.K.; Kim, D.-S. The Role of RNF213 4810 G > A and 4950 G > A Variants in Patients with Moyamoya Disease in Korea. Int. J. Mol. Sci. 2017, 18, 2477. [CrossRef]

22. Ohkubo, K.; Sakai, Y.; Inoue, H.; Akamine, S.; Ishizaki, Y.; Matsushita, Y.; Sanefuji, M.; Torisu, H.; Ihara, K.; Sardiello, M.; et al. Moyamoya disease susceptibility gene RNF213 links inflammatory and angiogenic signals in endothelial cells. Sci. Rep. 2015, 5, 13191. [CrossRef] [PubMed]

23. Sonobe, S.; Fujimura, M.; Niizuma, K.; Nishijima, Y.; Ito, A.; Shimizu, H.; Kikuchi, A.; Arai-Ichinoi, N.; Kure, S.; Tominaga, T. Temporal profile of the vascular anatomy evaluated by 9.4-T magnetic resonance angiography and histopathological analysis in mice lacking RNF213: A susceptibility gene for moyamoya disease. Brain Res. 2014, 1552, 64-71. [CrossRef] [PubMed]

24. Zhou, S.; Ambalavanan, A.; Rochefort, D.; Xie, P.; Bourassa, C.V.; Hince, P.; Dionne-Laporte, A.; Spiegelman, D.; Gan-Or, Z.; Mirarchi, C.; et al. RNF213 Is Associated with Intracranial Aneurysms in the French-Canadian Population. Am. J. Hum. Genet. 2016, 99, 1072-1085. [CrossRef] [PubMed]

25. Kim, J.S.; Lee, H.B.; Kwon, H.S. RNF213 Polymorphism in Intracranial Artery Dissection. J. Stroke 2018, 20, 404-406. [CrossRef] [PubMed]

26. Lin, J.; Sheng, W. RNF213 Variant Diversity Predisposes Distinct Populations to Dissimilar Cerebrovascular Diseases. Biomed Res. Int. 2018, 2018, 6359174. [CrossRef]

27. Jang, M.-A.; Chung, J.-W.; Yeon, J.Y.; Kim, J.-S.; Hong, S.C.; Bang, O.Y.; Ki, C.-S. Frequency and significance of rare RNF213 variants in patients with adult moyamoya disease. PLoS ONE 2017, 12, e0179689. [CrossRef]

28. Liu, W.; Hitomi, T.; Kobayashi, H.; Harada, K.H.; Koizumi, A. Distribution of moyamoya disease susceptibility polymorphism p.R4810K in RNF213 in East and Southeast Asian populations. Neurol. Med. Chir. 2012, 52, 299-303. [CrossRef]

29. Raso, A.; Biassoni, R.; Mascelli, S.; Nozza, P.; Ugolotti, E.; DI Marco, E.; DE Marco, P.; Merello, E.; Cama, A.; Pavanello, M.; et al. Moyamoya vasculopathy shows a genetic mutational gradient decreasing from East to West. J. Neurosurg. Sci. 2016. Published electronically October 27. Available online: https://www. minervamedica.it/en/journals/neurosurgical-sciences/article.php?cod=R38Y9999N00A16102701 (accessed on 10 March 2020).

30. Guey, S.; Kraemer, M.; Hervé, D.; Ludwig, T.; Kossorotoff, M.; Bergametti, F.; Schwitalla, J.C.; Choi, S.; Broseus, L.; Callebaut, I.; et al. Rare RNF213 variants in the C-terminal region encompassing the RING-finger domain are associated with moyamoya angiopathy in Caucasians. Eur. J. Hum. Genet. 2017, 25, 995-1003. [CrossRef]

31. Xue, S.; Cheng, W.; Wang, W.; Song, X.; Wu, J.; Song, H. The association between the ring finger protein 213 gene R4810K variant and intracranial major artery stenosis/occlusion in the Han Chinese population and high-resolution magnetic resonance imaging findings. Brain Circ. 2018, 4, 33-39.

32. Bang, O.Y.; Chung, J.-W.; Cha, J.; Lee, M.J.; Yeon, J.Y.; Ki, C.-S.; Jeon, P.; Kim, J.-S.; Hong, S.C. A Polymorphism in RNF213 Is a Susceptibility Gene for Intracranial Atherosclerosis. PLoS ONE 2016, 11, e0156607. [CrossRef] [PubMed]

33. Bang, O.Y.; Ryoo, S.; Kim, S.J.; Yoon, C.H.; Cha, J.; Yeon, J.Y.; Kim, K.H.; Kim, G.-M.; Chung, C.-S.; Lee, K.H.; et al. Adult Moyamoya Disease: A Burden of Intracranial Stenosis in East Asians? PLoS ONE 2015, 10, e0130663. [CrossRef] [PubMed] 
34. Kim, E.-H.; Yum, M.-S.; Ra, Y.-S.; Park, J.B.; Ahn, J.S.; Kim, G.-H.; Goo, H.W.; Ko, T.-S.; Yoo, H.-W. Importance of RNF213 polymorphism on clinical features and long-term outcome in moyamoya disease. J. Neurosurg. 2016, 124, 1221-1227. [CrossRef] [PubMed]

35. Matsuda, Y.; Mineharu, Y.; Kimura, M.; Takagi, Y.; Kobayashi, H.; Hitomi, T.; Harada, K.H.; Uchihashi, Y.; Funaki, T.; Miyamoto, S.; et al. RNF213 p.R4810K Variant and Intracranial Arterial Stenosis or Occlusion in Relatives of Patients with Moyamoya Disease. J. Stroke Cereb. Dis. 2017, 26, 1841-1847. [CrossRef] [PubMed]

36. Okazaki, S.; Morimoto, T.; Kamatani, Y.; Kamimura, T.; Kobayashi, H.; Harada, K.; Tomita, T.; Higashiyama, A.; Takahashi, J.C.; Nakagawara, J.; et al. Moyamoya Disease Susceptibility Variant RNF213 p.R4810K Increases the Risk of Ischemic Stroke Attributable to Large-Artery Atherosclerosis. Circulation 2019, 139, 295-298. [PubMed]

37. Morimoto, T.; Mineharu, Y.; Ono, K.; Nakatochi, M.; Ichihara, S.; Kabata, R.; Takagi, Y.; Cao, Y.; Zhao, L.; Kobayashi, H.; et al. Significant association of RNF213 p.R4810K, a moyamoya susceptibility variant, with coronary artery disease. PLOS ONE 2017, 12, e0175649. [CrossRef]

38. Fukushima, H.; Takenouchi, T.; Kosaki, K. Homozygosity for moyamoya disease risk allele leads to moyamoya disease with extracranial systemic and pulmonary vasculopathy. Am. J. Med. Genet. A 2016, 170, 2453-2456. [CrossRef]

39. Kim, D.-K.; Chang, S.-A.; Park, T.K. Moyamoya Disease: Cardiologist's Perspectives. J. Lipid Atheroscler. 2016, 5, 115-120. [CrossRef]

40. Wu, Z.; Jiang, H.; Zhang, L.; Xu, X.; Zhang, X.; Kang, Z.; Song, D.; Zhang, J.; Guan, M.; Gu, Y. Molecular analysis of RNF213 gene for moyamoya disease in the Chinese Han population. PLoS ONE 2012, 7, e48179. [CrossRef]

41. Zhang, Q.; Liu, Y.; Zhang, D.; Wang, R.; Zhang, Y.; Wang, S.; Yu, L.; Lu, C.; Liu, F.; Zhou, J.; et al. RNF213 as the major susceptibility gene for Chinese patients with moyamoya disease and its clinical relevance. J. Neurosurg. 2017, 126, 1106-1113. [CrossRef]

42. Shinya, Y.; Miyawaki, S.; Imai, H.; Hongo, H.; Ono, H.; Takenobu, A.; Nakatomi, H.; Teraoka, A.; Saito, N. Genetic Analysis of Ring Finger Protein 213 (RNF213) c.14576G>A in Intracranial Atherosclerosis of the Anterior and Posterior Circulations. J. Stroke Cereb. Dis. 2017, 26, 2638-2644. [CrossRef] [PubMed]

43. Kamimura, T.; Okazaki, S.; Morimoto, T.; Kobayashi, H.; Harada, K.; Tomita, T.; Higashiyama, A.; Yoshimoto, T.; Takahashi, J.C.; Nakagawara, J.; et al. Prevalence of RNF213 p.R4810K Variant in Early-Onset Stroke With Intracranial Arterial Stenosis. Stroke 2019, 50, 1561-1563. [CrossRef] [PubMed]

44. Akagawa, H.; Mukawa, M.; Nariai, T.; Nomura, S.; Aihara, Y.; Onda, H.; Yoneyama, T.; Kudo, T.; Sumita, K.; Maehara, T.; et al. Novel and recurrent RNF213 variants in Japanese pediatric patients with moyamoya disease. Hum. Genome Var. 2018, 5, 17060. [CrossRef] [PubMed]

45. Bang, O.Y.; Toyoda, K.; Arenillas, J.F.; Liu, L.; Kim, J.S. Intracranial Large Artery Disease of Non-Atherosclerotic Origin: Recent Progress and Clinical Implications. J. Stroke 2018, 20, 208-217. [CrossRef]

46. Research Committee on the Pathology and Treatment of Spontaneous Occlusion of the Circle of Willis; Health Labour Sciences Research Grant for Research on Measures for Infractable Diseases. Guidelines for diagnosis and treatment of moyamoya disease (spontaneous occlusion of the circle of Willis). Neurol. Med. Chir. 2012, 52, 245-266. [CrossRef]

47. Chimowitz, M.I.; Lynn, M.J.; Howlett-Smith, H.; Stern, B.J.; Hertzberg, V.S.; Frankel, M.R.; Levine, S.R.; Chaturvedi, S.; Kasner, S.E.; Benesch, C.G.; et al. Comparison of warfarin and aspirin for symptomatic intracranial arterial stenosis. N. Engl. J. Med. 2005, 352, 1305-1316. [CrossRef]

48. Barrett, J.C.; Fry, B.; Maller, J.; Daly, M.J. Haploview: Analysis and visualization of LD and haplotype maps. Bioinformatics 2005, 21, 263-265. [CrossRef]

(C) 2020 by the authors. Licensee MDPI, Basel, Switzerland. This article is an open access article distributed under the terms and conditions of the Creative Commons Attribution (CC BY) license (http://creativecommons.org/licenses/by/4.0/). 